\title{
一座季节性休渔湖泊一一洱海轮虫的季节动态特征”
}

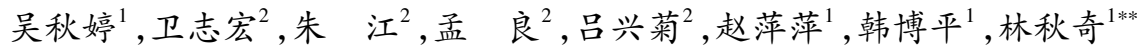 \\ ( 1 : 暨南大学水生生物研究所,广州 510632 ) \\ $(2$ : 洱海湖泊研究中心, 大理 671000$)$
}

\begin{abstract}
摘 要: 于 2009 年 2-11 月对洱海轮虫进行月际采样, 分析洱海轮虫的多样性及其群落结构季节动态特征. 洱海作为一 个高原湖泊, 其轮虫种类组成仍然呈现出热带一亚热带的主要特征. 本研究共鉴定轮虫 68 种, 多数种类为广布性或暖水性 种类, 隶属 17 科 25 属, 异尾轮属、腔轮属和臂尾轮属是种类最多的三个属, 占鉴定轮虫种类的 $37 \%$. Lecane arcuata 和 Trichocera inermis 为我国新纪录种. 轮虫生物量的季节分布呈 “双峰型”, 并分别出现在休渔期的中期和捕鱼期前期. 在休渔 期中期, 轮虫主要以前节晶囊轮虫为优势种; 在捕鱼期前期, 轮虫先以螺形龟甲轮虫和广生多肢轮虫为优势, 后以前节晶 囊轮虫为优势. 季节性休渔不仅使鱼类对轮虫的捕食压力出现季节性变化, 而且还通过影响枝角类的群落结构改变枝角 类对轮虫的竞争压力. 在捕食和竞争的双重作用下, 轮虫主要以大型杂食性种类一一前节晶囊轮虫为优势种类, 并呈现 “双峰型”的季节分布模式.
\end{abstract}

关键词: 轮虫;多样性;群落结构;季节性休渔;洱海

\section{Seasonal dynamics of rotifer in a seasonal fishing moratorium lake - Lake Erhai, Yun- nan Province, China}

WU Qiuting ${ }^{1}$, WEI Zhihong ${ }^{2}$, ZHU Jiang ${ }^{2}$, MENG Liang ${ }^{2}$, LÜ Xingju ${ }^{2}$, ZHAO Pingping ${ }^{1}$, HAN Boping ${ }^{1} \&$ LIN Qiuqi ${ }^{1}$

(1: Institute of Hydrobiology, Jinan University, Guangzhou 510632, P. R. China)

(2: Research Center of Lake Erhai, Dali 671000, P. R. China)

Abstract: Rotifers were sampled monthly from February to November in 2009 in Lake Erhai, Yunnan Province, China, in order to study their diversity and seasonal dynamics. Lake Erhai has a rotifer composition with tropical-subtropical characteristics: 68 species belonging to 25 genera of 17 families were identified, the majority of which were eurythermal or mesophilic. The genera of Trichocerca, Lecane and Brachionus were more abundant than others, accounting for $37 \%$ of the total community. Lecane arcuata and Trichocera inermis are new records in China. Biomass of the rotifer communities in Lake Erhai exhibited a bimodal seasonal cycle. An increase occurred during spring from low winter levels to an annual maximum in the mid fishing moratorium and a second increase in the early fishing season. In the mid fishing moratorium, the rotifer biomass was dominated by Asplanchna priodonta; while in the early fishing season, it was dominated by the small-sized Keratella cochlearis and Polyarthra vulgaris, then by A. priodonta again. The seasonal fishing moratorium affected not only the predation pressure on rotifers, but also competitive pressure on rotifer through influencing the community structure of Cladocera. Through the influence of predation and competition, rotifers were dominated by large omnivorous $A$. priodonta, which showed a bimodal seasonal distribution pattern.

Keywords: Rotifers; diversity; community structure; seasonal fishing moratorium; Lake Erhai

轮虫体型小、繁殖速度快、种类繁多, 是淡水水体中浮游动物类群之一 ${ }^{[1-2]}$. 影响轮虫群落结构的因素包 括非生物因素和生物因素,非生物因素主要是光照、温度、营养盐、食物等,生物因素有捕食和竞争等 ${ }^{[34]}$. 而

* 教育部博士点基金新老师类项目 (20094401120009) 和国家水体污染控制与治理科技重大专项项目 (2009ZX07105-01-001) 联合资助. 2011-08-04 收稿;2011-11-18 收修改稿. 吴秋婷, 女, 1986 年生, 硕士研究 生;E-mail:wuqiuting_311@163.com.

** 通信作者;E-mail:tlinqq@jnu. edu.cn. 
通常认为在淡水生态系统中, 生物之间的相互作用是影响其群落动态和结构的关键因素 ${ }^{[5]}$. Iglesias 等认为 在热带一亚热带水体中, 捕食是影响浮游动物群落结构的决定性因素 ${ }^{[6]}$, 鱼类和一些肉食性或杂食性的浮 游动物是轮虫的主要捕食者 ${ }^{[7]}$. 由于食物生态位的重叠, 轮虫与枝角类存在食物竞争关系 ${ }^{[8]}$. 在捕食压力比 较低的温带水体中, 枝角类通常以溞属各种类为优势, 而溞属各种类在与轮虫的食物竞争中都能取得绝对 优势 ${ }^{[9-10]}$; 相反, 在捕食压力比较大的水体中, 浮游动物通常以小型枝角类、桡足类或轮虫为优势 ${ }^{[11-12]}$.

洱海是我国云贵高原上的第二大淡水湖, 属澜沧江水系, 位于大理白族自治州中心 $\left(18^{\circ} 10^{\prime} \sim 20^{\circ} 10^{\prime} \mathrm{N}\right.$, $108^{\circ} 37^{\prime} \sim 111^{\circ} 03^{\prime} \mathrm{E}$ ), 平均水深 $11.1 \mathrm{~m}$, 容积 $2.79 \times 10^{9} \mathrm{~m}^{3}$. 洱海作为当地渔业发展基地, 2009 年鱼类捕捞 量约为 $120 \mathrm{~kg} / \mathrm{hm}^{2}$. 为了提高渔业产量, 洱海于 2004 年开始实行全湖季节性休渔, 每年的 $2-6$ 月为休渔 期. 季节性休渔对大型枝角类盔形掻的季节动态产生较大的影响 ${ }^{[13-14]}$, 在洱海休渔期早期, 由于水温较 低, 鱼类对大型枝角类的捕食压力也相对较低, 浮游动物群落以盔形溞占优势; 随着水温的上升, 鱼类捕 食压力的增大, 盔形溞的优势度逐渐下降, 并在休渔期末期从水柱中消失 ${ }^{[15]}$. 盔形溞种群的季节性动态变 化导致其对轮虫的食物竞争压力也出现明显的季节性变化. 那么, 面对竞争压力的季节性变化, 轮虫是如 何响应的? 与此同时, 季节性休渔导致捕食压力的季节性变化对轮虫群落结构又能产生怎样的影响? 另 外, 轮虫虽然分布广泛, 但其具有明显的地理分布模式; 水体中轮虫种类组成特征主要取决于其所在的地 理分区 ${ }^{[16-17]}$. 洱海地处云贵高原, 轮虫有其独特的区域分布特征. 本文通过调查分析洱海轮虫的多样性及 其群落结构季节动态, 探讨洱海轮虫种类组成的区域特征以及季节性休渔对轮虫群落结构动态的影响 作用.

\section{1 材料与方法}

\section{1 采样方法}

于 2009 年 2-11 月对洱海浮游动物进行月际采样 (1、6 和 12 月 份样品丢失), 共设置 7 个采样点, 北湖区 3 个点, 南湖区 4 个点, 具体 位置详见图 1 .

定性样品用 $25^{\#}$ 浮游生物网 (64 $\left.\mu \mathrm{m}\right)$ 于水平及垂直方向拖网; 定 量样品用 $10 \mathrm{~L}$ 采水器从表层至底层每隔 $2 \mathrm{~m}$ 进行采集, 共采水 $50 \mathrm{~L}$, 并 现场用 $38 \mu \mathrm{m}$ 浮游生物网过滤. 所有样品均用 $5 \%$ 的福尔马林溶液固 定, 在显微镜和解剖镜下鉴定种类和计数, 轮虫分类主要依据 Kost 的分 类体系 ${ }^{[18]}$. 此外, 定量样品还需测定轮虫的体长、体宽以计算每个个体的 体积, 并认为轮虫的密度与水的密度 (密度为 $1 \mathrm{~g} / \mathrm{ml}$ ) 相同, 计算个体湿 重, 最后根据轮虫体积的近似计算公式计算其的生物量 ${ }^{[19]}$. 水质理化 指标和鱼类数据由洱海湖泊研究中心提供,用塞氏罗盘测定透明度 (SD), 叶绿素 a 浓度 (Chl. a) 的测定采用反复冻融一浸提法 ${ }^{[20]}$, 总磷 $(\mathrm{TP}) 、$ 正磷酸盐态磷 $\left(\mathrm{PO}_{4}^{3-}-\mathrm{P}\right)$ 、总氮 $(\mathrm{TN})$ 、硝态氮 $\left(\mathrm{NO}_{3}^{-}-\mathrm{N}\right)$ 、亚硝态 氮 $\left(\mathrm{NO}_{2}^{-}-\mathrm{N}\right)$ 和铵态氮 $\left(\mathrm{NH}_{4}^{+}-\mathrm{N}\right)$ 均按照国家水质标准 $\mathrm{GB} / \mathrm{T} 3838$ 2002 进行测定.

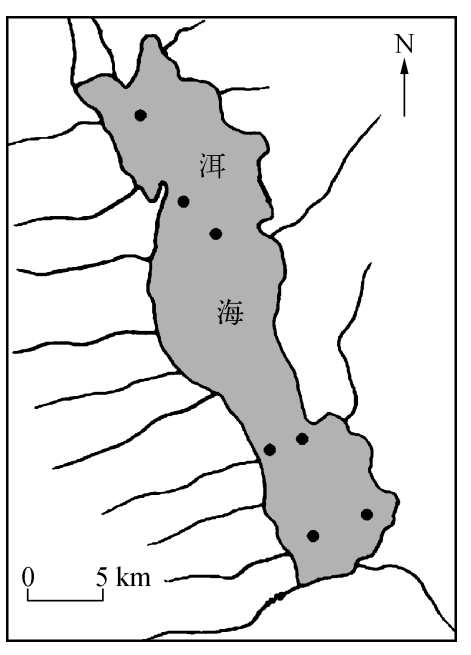

图 1 洱海采样点分布

Fig. 1 Distribution of sampling sites in Lake Erhai

\section{2 数据分析}

实验数据用 SPSS 16.0 软件进行 One-way ANOVA 分析, $P<0.05$ 表示具有显著差异.

\section{2 结果与分析}

\section{1 理化指标的季节变化}

洱海地处亚热带, 全年水温差大约 $13{ }^{\circ} \mathrm{C}$, 本次调查期间平均温度为 $18.9{ }^{\circ} \mathrm{C}$, 最低水温 $\left(11.0{ }^{\circ} \mathrm{C}\right)$ 出现在 2 月, 最高水温 $\left(23.8^{\circ} \mathrm{C}\right)$ 出现在 9 月. Chl. a 浓度变化范围为 $4.8 \sim 24.3 \mu \mathrm{g} / \mathrm{L}$, 最低浓度出现在 2 月, 最高浓 度出现在 10 月, $8-12$ 月 Chl. a 浓度持续较高. SD 的变化趋势与 Chl. a 浓度相反, 在 $2-3$ 月份出现一个清 水期, $\mathrm{SD}$ 达到 $3 \mathrm{~m}$ 左右. $\mathrm{TP}$ 变化范围为 $0.01 \sim 0.04 \mathrm{mg} / \mathrm{L}, \mathrm{TN}$ 变化范围为 $0.5 \sim 0.8 \mathrm{mg} / \mathrm{L}$, 在 $7-9$ 月份 $\mathrm{TP}$ 、 
$\mathrm{TN}$ 浓度出现高峰,此时水体营养水平较高(图 2).
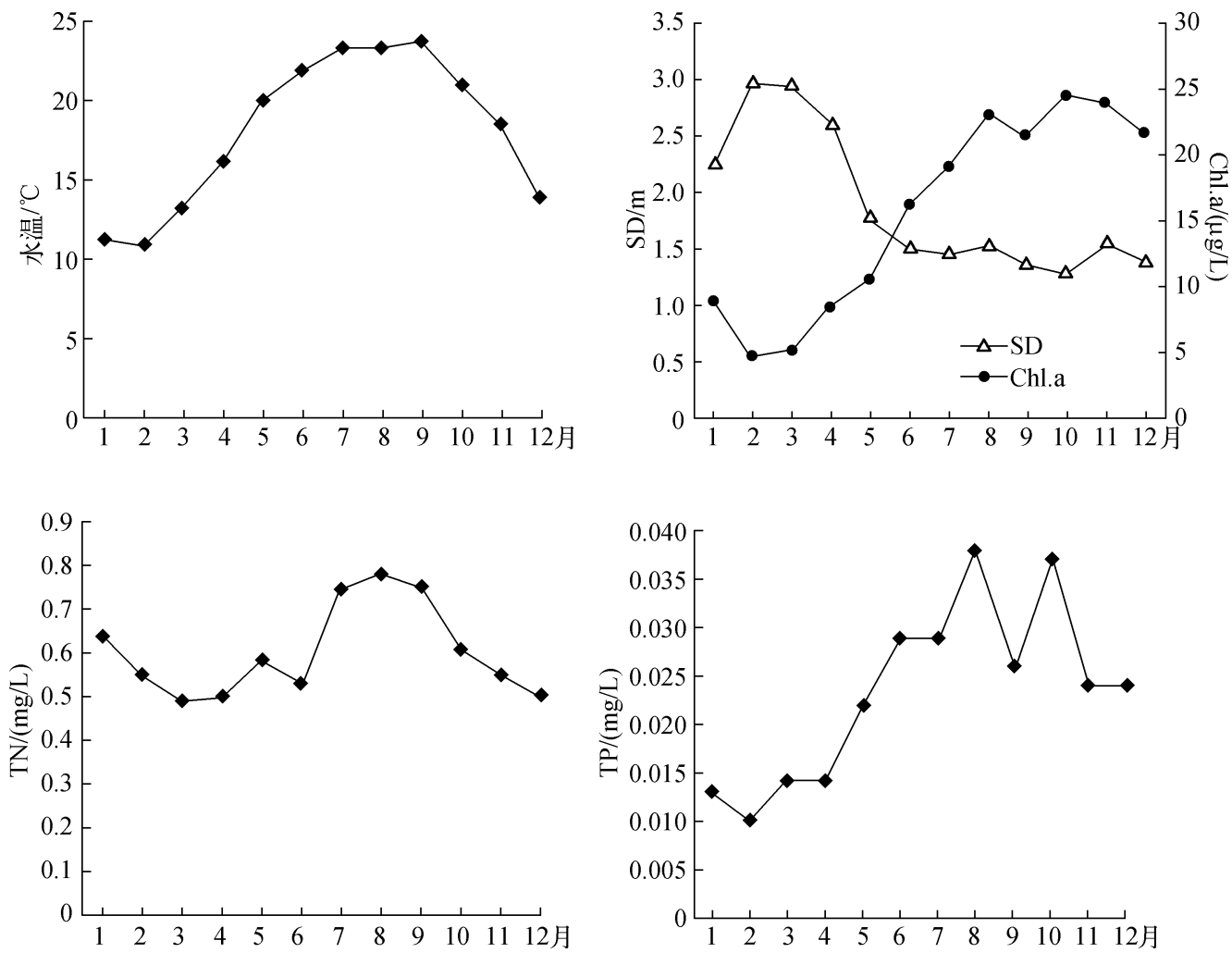

图 2 洱海 2009 年水温、透明度、叶绿素 a 浓度、总氮浓度和总磷浓度的季节变化

Fig. 2 Seasonal changes of water tempreture, SD, chlorophyll-a, TN and TP concentrations in Lake Erhai in 2009

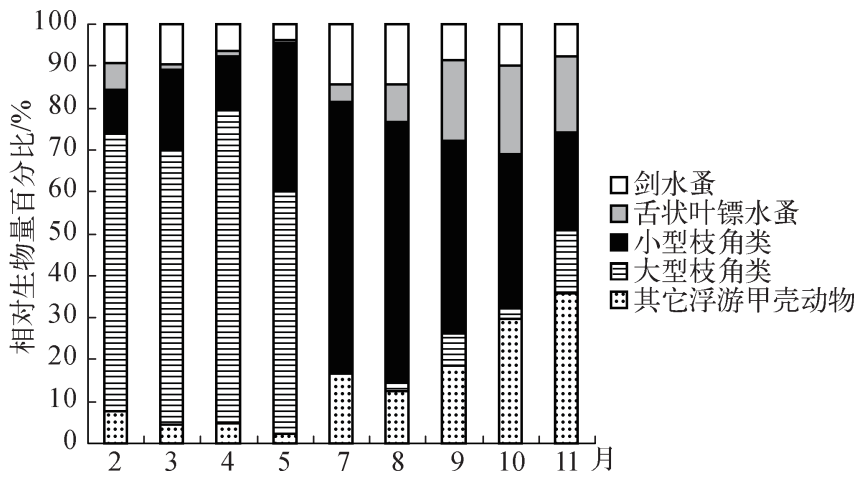

图 3 洱海 2009 年浮游甲壳动物优势种类 相对生物量和季节变化

Fig. 3 Seasonal variations of relative biomass of the dominant zooplankton crustacean in Lake Erhai in 2009

\section{2 浮游甲壳动物的季节变化}

洱海浮游甲壳动物以枝角类为优 势, 在休渔期的早期和中期, 枝角类的 生物量主要由大型枝角类贡献, 以盔形 溞 (Daphnia galeata) 和模糊网纹溞 ( Ceriodaphnia dubia) 占优势, 盔型溞在清 水期 (2-3 月份) 形成一个高峰; 休渔 期晚期到捕鱼中期以小型枝角类占优 势, 主要包括长额象鼻溞 (Bosmina longirostris)、圆形盘肠溞(Chydorus sphaericus) 和方形网纹溞 (Ceriodaphnia qudrangula), 桡足类在此阶段也不断发展 壮大,剑水蚤 ( 指剑水蚤目的浮游甲壳 动物) 在清水期出现了生物量高峰 (图 $3)$, 盔形溞从水柱中消失.

\section{3 轮虫种类组成}

此次调查共鉴定轮虫 68 种,其中国内新纪录种 2 种 (Lecane arcuata 和 Trichocera inermis), 绝大多数种类 属于单巢类. 其中, 异尾轮科 14 种、臂尾轮科 9 种、疮毛轮科 8 种、腔轮科 6 种和腹尾轮科 6 种. 常见种类为 
螺形龟甲轮虫 (Keratella cochlearis)、对棘异尾轮虫 (Trichocerca similis)、圆筒异尾轮虫 ( T. cylindrica)、长刺异 尾轮虫 ( $T$. longiseta)、前节晶囊轮虫 (Asplanchna priodonta)、广生多肢轮虫 (Polyarthra vulgaris)、大肚须足轮 虫 (Euchlanis dilatata)、扁平泡轮虫 (Pompholyx complanata)、长圆疮毛轮虫 (Synchaeta oblonga)、独角聚花轮 虫 (Conochilus unicornis)、Lecane arcuata、无常胶鞘轮虫 (Collotheca mutabilis) 和舞跃无柄轮虫 (Ascomorpha saltans) 等. Lecane arcuata 和 Trichocera inermis 为我国新纪录种.

\section{4 轮虫群落结构}

洱海轮虫丰度季节性变化明显, 基本呈现“双峰型”, 丰度变化范围为 $6 \sim 753$ ind. / $\mathrm{L}$, 平均丰度为 278 ind. $/ \mathrm{L}$, 最高丰度出现在 5 月, 最低丰度出现在 2 月 (图 4a). 洱海轮虫生物量变化范围为 $1 \sim 344 \mu \mathrm{g} / \mathrm{L}, 2$ 月生物量最低 $(9 \mu \mathrm{g} / \mathrm{L}), 4$ 月生物量达到最大 $(191 \mu \mathrm{g} / \mathrm{L})$. 轮虫生物量季节变化趋势也基本呈现 “双峰型” (图 4b) , 第一个峰值出现在休渔期中期的 4 月份, 以前节晶囊轮虫为优势,第二个峰值则出现在捕鱼期前期 的 8 月份, 以螺形龟甲轮虫、广生多肢轮虫和前节晶囊轮虫等为优势 (图 5 ). 前节晶囊轮虫、长圆疮毛轮虫、 螺形龟甲轮虫、广生多肢轮虫、对棘异尾轮虫和圆筒异尾轮虫是洱海轮虫的主要种类. 除在 $5-8$ 月份以外, 前节晶囊轮虫所占总生物量的比例均在 $50 \%$ 以上, 是洱海绝对优势种类, 其生物量的季节性变化趋势与轮 虫总生物量相似, 呈 “双峰型”, 第一个峰值同样出现在休渔期中期的 4 月份, 而第二个峰值则出现在捕鱼期 中期的 10 月份 (图 5). 螺形龟甲轮虫、广生多肢轮虫、长圆疮毛轮虫、对棘异尾轮虫和圆筒异尾轮虫的季节 性变化则基本上呈 “单峰型”. 其中, 长圆病毛轮虫、对棘异尾轮虫和圆筒异尾轮虫的峰值出现在休渔期中 期, 但是滞后于前节晶囊轮虫的第一个峰值的 5 月份; 螺形龟甲轮虫和广生多肢轮虫的峰值则出现在捕鱼 期前期的 8 月份, 先于前节晶囊轮虫的第二个峰值.

相对于洱海轮虫明显的季节变化而言,其空间变化不显著. 用 SPSS 16.0 软件分别分析了洱海南、北湖 区轮虫的丰度和生物量, 结果显示南、北湖区之间差异不显著.
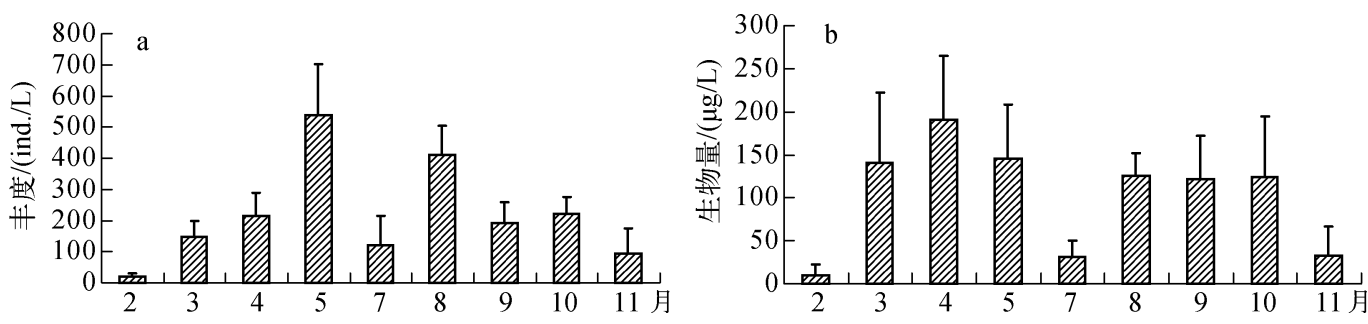

图 42009 年洱海轮虫平均丰度 (a) 和生物量 (b) 的季节变化

Fig. 4 Seasonal dynamics of mean abundance(a) and biomass(b) of rotifers in Lake Erhai in 2009

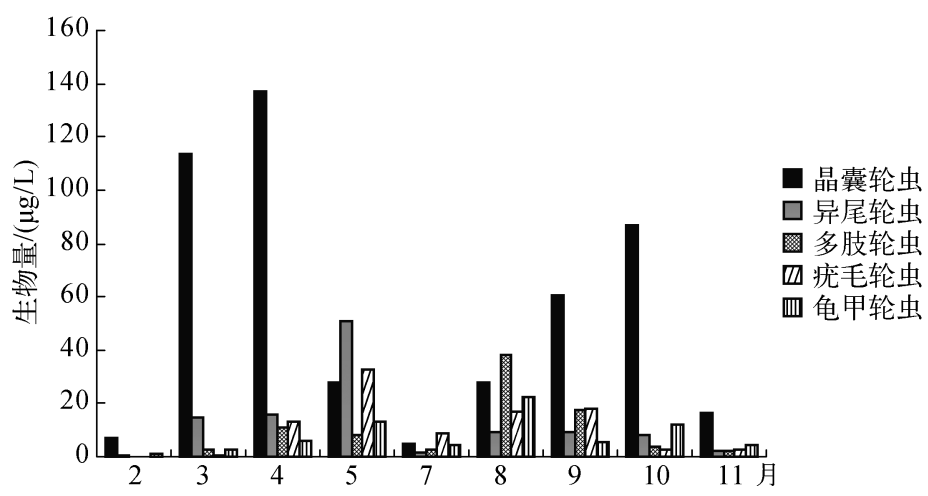

图 5 洱海 2009 年轮虫优势种类生物量的季节变化

Fig. 5 Seasonal variations of biomass of the dominant rotifer species in Lake Erhai in 2009 


\section{3 讨论}

\section{1 种类组成}

从时间尺度上看, 近几十年来洱海富营养化程度不断加剧, 其轮虫的多样性降低, 2009 年在洱海样品中 共鉴定轮虫 68 种, 显著少于董云仙在 1985-1990 年对洱海轮虫的调查结果 ${ }^{[21]}$. 从区域尺度上看,热带、亚 热带地区和温带地区轮虫种类组成的差异主要来自于少数几个属, 它们在分布上存在地区性限制 ${ }^{[17]}$. 腔轮 属、臂尾轮属和异尾轮属的种类集中分布于热带和亚热带地区,并是该地区轮虫的优势种类 ${ }^{[22-24]}$, 而在温带 地区水体中虽然也有分布, 但只有少数几种; 龟甲轮属、巨头轮属、叶轮属和疮毛轮属在热带和亚热带地区 也有分布, 并且某些种类分布相当广泛或为该地区特有种 (如热带龟甲轮虫), 但绝大多数种类主要分布于 温带地区 ${ }^{[25]}$. 洱海地处亚热带, 与其它热带一亚热带地区水体一样, 腔轮属、臂尾轮属和异尾轮属是种类最 多的三个属,共占鉴定出轮虫种类的 $37 \%$.

鉴定的 6 种腔轮属轮虫均为广布性种类,但以 Lecane arcuata 最为常见,全年均有分布. Lecane arcuata 虽 为广布性种类,但是在我国尚未见报导,属我国的新记录种. 臂尾轮属共鉴定出 5 种,多为广布性或暖水性 种类, 但在洱海并不常见. 洱海轮虫样品中鉴定出的异尾轮属种类最多, 有 14 种, 在这些种类中, 多为广布 性种类, 其中卡顿异尾轮虫 (Trichocerca chattoni) 是暖水性种类; 圆筒异尾轮虫和罗氏异尾轮虫 ( T. roussele$t i)$ 是冷水性种类 ${ }^{[26]}$, 但在洱海样品中全年均可见, 说明这些冷水性种类在亚热带地区也有分布, 林秋奇在 广东省热带与亚热带过渡地区一一流溪河水体中也发现圆筒异尾轮虫全年均有出现 ${ }^{[3]}$. 洱海属于亚热带水 体,温度的季节变化比较明显,最低温度可达 $11.0{ }^{\circ} \mathrm{C}$,这些因素均可导致洱海轮虫分布的特异性.

\section{2 轮虫群落结构调控因素}

温度是非生物因素中影响轮虫群落结构季节变化的一个重要因素, 可以通过影响轮虫的新陈代谢、捕 食压力和竞争强度, 直接或间接地影响其群落结构变化 ${ }^{[8,27]}$. 洱海地处亚热带高原, 最高水温只有 $23.8^{\circ} \mathrm{C}$, 而最低水温为 $11.0^{\circ} \mathrm{C}$ ( 图 2). 在 10-12 月份, 虽然叶绿素 a 浓度明显高于其它季节 (图 2), 捕食压力和竞争 强度均低于其它季节, 但是受较低水温的影响, 轮虫生长相对缓慢, 总生物量处于全年较低水平. 随着水温 的上升, 轮虫的生长速率有所升高, 但捕食压力和盔形溞的食物竞争强度也相应增大, 轮虫群落结构出现明 显的动态变化.

每年的 2-6月是洱海的休渔期,且在 2 月份向湖中投放一定规格的鲢、鳙等滤食性鱼类的鱼苗, 2009 年共投放鱼种 (规格 $50 \sim 250 \mathrm{~g} /$ 尾) $3.5 \times 10^{5} \mathrm{~kg}$; 7 月是捕获太湖新银鱼 (Neosalanx taihuensis Chen) 的主要时 期, 在这一时期洱海只允许捕捞银鱼, 捕捞量约 $28 \mathrm{~kg} / \mathrm{hm}^{2}$; 从 8 月份开始, 可以捕获其它鱼类, 其中鲢、鳙等 滤食性鱼类的捕获量约为 $89 \mathrm{~kg} / \mathrm{hm}^{2}$. 季节性休渔的实施以及温度的季节性变化导致鱼类的捕食压力出现 明显的季节性变化. 鲢、鳙属滤食性鱼类,它们对浮游动物并没有主动的选择能力, 捕食效率主要取决于浮 游动物的逃避能力 ${ }^{[28-30]}$. 一般来说, 轮虫和枝角类的逃避能力小于桡足类, 更易于被滤食; 而在枝角类中, 溞 属各种类的逃避能力比较弱, 很容易被滤食 ${ }^{[31]}$. 太湖新银鱼作为洱海鱼类的优势种之一, 是一年生的小型鱼 类, 常选择性地捕食盔形溞和秀体溞等大型枝角类 ${ }^{[32]}$, 盔形溞作为洱海浮游动物群落的优势种, 是太湖新银 鱼主要的捕食对象. 吴庆龙等研究表明银鱼的引人导致了洱海浮游动物生物量大幅下降, 其对浮游动物群 落的调控作用显著 ${ }^{[33]}$. 鲢鱼、鳙鱼、太湖新银鱼等鱼类捕食强度的季节性变化对洱海盔形溞的季节性动态产 生重大的影响 ${ }^{[15]}$, 从而使盔形溞对轮虫的竞争压力产生明显的变化.

众多研究表明,在捕食压力比较低的温带水体中,枝角类通常以溞属各种类为优势, 而溞属各种类在与 轮虫的食物竞争中都能取得绝对优势 ${ }^{[9-10]}$; 相反, 在捕食压力比较大的水体中, 浮游动物通常以小型枝角类、 桡足类或轮虫为优势 ${ }^{[11-12]}$. 在洱海休渔期的早期, 由于水温较低,银鱼等鱼类对盔形溞的捕食压力相对较 低,盔形溞种群得以增长并成为浮游动物优势种类 (图 3). 此时, 洱海也相应出现一个清水期, 叶绿素 a 浓度 只有清水期前的 $1 / 3$ 左右 (图 2). 在清水期, 盔形溞虽然对一些牧食性的轮虫种类施加很大的竞争压力, 但 轮虫仍然在清水期出现一个以前节晶囊轮虫为优势种的峰值. 前节晶囊轮虫是一种杂食性的轮虫种类, 既 可以摄食浮游植物, 也可以其它轮虫或小型枝角类为食, 如螺形龟甲轮虫和长额象鼻溞 ${ }^{[34-35]}$, 所以它可以通 过改变食性来应对食物竞争压力, 从而使其种群得以增长, 成为轮虫优势种类, 并在清水期出现一个峰值. 
另外, 桡足类也在清水期出现一个小峰值, 而且以中剑水蚤为优势 (图 3). 中剑水蚤也是一种杂食性种类, 喜 食适口性软体动物, 以轮虫或小型枝角类为食 ${ }^{[36]}$. 螺形龟轮虫、广生多肢轮虫等一些小型轮虫种类既要面对 盔形溞的食物竞争压力, 又被前节晶囊轮虫和中剑水蚤等捕食, 在清水期并不占优势 (图 4b). 在休渔期中 期, 随着水温的上升以及鱼类的自身生长, 它们对浮游动物的捕食压力越来越大, 银鱼等鱼类对盔形溞的选 择性捕食导致盔形溞种群密度大幅度下降, 银鱼不得不同时捕食其它体型相对较大的浮游动物种类. 前节 晶囊轮虫作为一种大型轮虫种类, 在洱海中最大体长可达到 $1 \mathrm{~mm}$ 左右, 很容易被选择性捕食, 从而导致其 生物量下降 ${ }^{[11]}$. 随着前节晶囊轮虫和盔形溞生物量的下降, 长圆疮毛轮虫、对棘异尾轮虫和圆筒异尾轮虫的 生物量在 5 月份出现一个短暂的峰值. 鲢、鳙鱼等滤食性鱼类与轮虫之间既存在食物竞争的关系, 又存在捕 食与被捕食的关系, 由于逃避能力很弱, 轮虫可以有效地被滤食性鱼类所滤食 ${ }^{[28,37]}$. 休渔期末期的 6 月和 7 月是滤食性鱼类对轮虫滤食压力最大的时期, 这时一方面水温比较高, 另一方面由于不允许开捕, 鱼类种群 密度处于高峰期. 虽然此时盔形溞已从水柱中消失, 枝角类对轮虫的食物竞争压力大为降低, 但由于来自 鲢、鳙鱼等滤食性鱼类的滤食压力的持续上升, 轮虫生物量仍然呈下降趋势. 虽然此时叶绿素 a 浓度高、浮 游植物丰度高, 但蓝藻占总藻类丰度的 70\% 80\%, 不能提供足够可食的有效食物, 更增加了鲢、鳙鱼等滤 食性鱼类对轮虫的滤食. 随着捕鱼期对鲢、鳙等滤食性鱼类的捕捞, 被滤食压力和食物竞争压力的下降使得 螺形龟甲轮虫和广生多肢轮虫这些小型轮虫种类的种群得以迅速增长, 并成为优势轮虫种类, 继而导致轮 虫生物量重新出现第二个峰值. 随后, 捕食压力的持续下降以及小型轮虫等食物的增加导致前节晶囊轮虫 替代螺形龟甲轮虫和广生多肢轮虫重新成为优势轮虫种类.

综上所述, 洱海水温的季节动态和季节性休渔引起捕食压力的季节性变化, 对轮虫和枝角类的群落结 构均具有一定的调节作用; 与此同时, 枝角类群落结构的季节动态导致了枝角类对轮虫的食物竞争压力季 节性变化明显, 并对轮虫群落结构也具有调节作用. 在捕食和竞争的双重影响下, 洱海轮虫主要以大型杂食 性种类一一前节晶囊轮虫为优势种类, 并呈现 “双峰型” 的季节分布模式. 作为一个高原湖泊, 其轮虫种类组 成仍然呈现出热带一亚热带的主要特征.

\section{4 参考文献}

[ 1 ] Scheda SM, Cowell BC. Rotifer grazers and phytoplankton: seasonal experiments on natural communities. Archiv für Hydrobiologie, 1988, 114 (1) : 31-44.

[ 2 ] Twombly S. Seasonal and short term fluctuations in zooplankton abundance in tropical lake Malawi. Limnol \& Oceanogr, $1983, \mathbf{2 8}(6): 1214-1224$.

[ 3 ] 林秋奇. 流溪河水库后生浮游动物多样性与群落结构的时空异质性 [学位论文]. 广州: 暨南大学, 2007.

[ 4 ] Berzins B, Pejler B. Rotifer occurance in relation to temperature. Hydrobiologia, 1989, 175(3) : $223-231$.

[ 5 ] Brönmark C, Hansson LA. The biology of lakes and ponds. New York: Oxford University Press, 2005 : 59.

[ 6 ] Iglesias C, Mazzeo N, Meerhoff M et al. High preadation is of key importance for dominance of smallbodied zooplankton in warm shallow lakes: evidence from lakes, fish exclosures and surface sediments. Hydrobiologia, 2011, 667 : 133-147.

[ 7 ] Starling FLRM, Rocha AJA. Experimental study of the impacts of planktivorous fishes on plankton community and eutrophication of a tropical Brazilian reservoir. Hydrobiologia, 1990, 200/201 : $581-591$.

[8] Gilbert JJ. Competition between rotifers and daphnia. Ecology, 1985, 66 (6) : 1943-1950.

[ 9 ] Brooks JL, Dondson SI. Predation, body size, and composition of plankton. Science, 1965, 150(3692) : 28-35.

[10] Dodson SI. Zooplankton competition and predation: an experimental test of the size-efficiency hypothesis. Ecology, 1974, $\mathbf{5 5}(3)$ : 605-613.

[11] Stenson JAE. Fish impact on rotifer community structure. Hydrobiologia, 1982, 87: 57-64.

[12] Fernando CH. Zooplankton, fish and fisheries in tropical freshwaters. Hydrobiologia, 1994, 272 : 105-123.

[13 ] Kramer AM, Drake JM. Experimental demonstration of population extinction due to a predator-driven Allee effect. Journal of Animal Ecology, 2010, 79: 633-639.

[14] Gilbert JJ. Suppression of rotifer populations by Daphnia: A review of the evidence, the mechanisms, and the effects on zooplankton community structure. Limnol \& Oceanogr, 1988, 33(6) : 1286-1303.

[15] Lin QQ, Zhao PP, Wu QT et al. Response of cladocerans to seasonal fishing moratorium in a subtropical plateau lake. Hy 
drobiology, 2012 (Received).

[16] Dumont HJ. Biogeography of rotifers. Hydrobiologia, 1983, 104: 19-30.

[17] Sládeĉek V. Rotifers as indicators of water quality. Hydrobiologia,1983, 100 : 169-201.

[18] Koste W. Rotatoria, Vol. 2. Berlin: Gebrüder Borntraeger,1978.

[19］章宗涉,黄祥飞. 淡水浮游生物研究方法. 北京:科学出版社,1991:1358-1362.

[20] 林少君,贺立静, 黄沛生等. 浮游植物中叶绿素 a 提取方法的比较与改进. 生态科学,2005,24(1):9-11.

[21］董云仙. 洱海轮虫及其与生态环境的关系. 云南环境科学,2003,22:106-108.

[22] Fernando CH. The freshwater zooplankton of Sri Lanka with a discussion of tropical freshwater zooplankton composition. Int Revue ges Hydrobiol,1980,65: 85-125.

[23] Fernando CH,Zankai NP. The Rotifera of Malaysia and Singapore with remarks on some species. Hydrobiologia, 1981, 78: 205-219.

[24] Segers H. Zoogeography of the Southeast Asian Rotifera. Hydrobiologia ,2001 ,446/447 :233-246.

[25] Green J. The temperate-tropical gradient of planktonic Protozoa and Rotifera. Hydrobiologia, 1994, 272 : 13-26.

[26] Segers H. A biogeographical analysis of rotifers of the genus Trichocerca Lammarck, 1801 ( Trichocercidae, Monogononta, Rotifera), with notes on taxonomy. Hydrobiologia, 2003, 500 : 103-114.

[27] Achenbach L, Lampert W. Effects of elevated temperatures on threshold food concentratins and possible competitive abilities of differently sized cladoceran species. Oikos, 1997, 79: 469-476.

[28] 李思发, 徐森林. 水库养鱼与捕食. 上海: 上海科学技术出版社, 1988.

[29] Drenner RW, Strickler JR, O'Brien WJ. Capture probability: the role of zooplankton escape in the selective feeding of planktivorous fish. J Fish Res Board Can, 1978, 35:1370-1373.

[30] Drenner RW, de Noyelles FJr, Kettle D. Selective impact of filter-feeding gizzard shad on zooplankton community structure. Limnol \& Oceanogr, 1982, 27 :965-968.

[31] Drenner RW, McComas SR. The role of zooplankter escape ability and fish size selectivity in the selective feeding and impact of planktivorous fish. Hanover, New Hampshire, USA: New England University Press, 1980: 587-593.

[32] Liu ZW. Diet of the zooplanktivorous icefish Neosalanx pseudotaihuensis Zhang. Hydrobiologia, 2001, 459: 51-56.

[33] 吴庆龙,王云飞. 洱海生物群落的历史演变分析. 湖泊科学, 1999,11(3):267-273.

[34] Kappes H, Mechenich C, Sinsch U. Long-term dynamics of Asplanchna priodonta in Lake Windsborn with comments on the diet. Hydrobiologia, 2000, 432 : 91-100.

[35] Pociecha A, Wilk-Wožniak E. Comments on the diet of Asplanchna priodonta (Gosse, 1850) in the Dobczycki dam reservoir on the basis of field sample observations. Oceanological and Hydrobiology Studies, 2008, XXXVII(3):63-69.

[36] Devetter M, Seda J. Regulation of rotifer community by predation of Cyclops vicin (Copepoda) in the Rímov Reservoir in spring. International Review of Hydrobiology, 2006, 92 (1) : 101-112.

[37] Shao ZJ, Xie P, Zhuge Y. Long-term changes of planktonic rotifers in subtropical Chinese lake dominated by filter-feeding fishes. Freshwater Biology, $2001, \mathbf{4 6}$ : 973-986. 